\title{
JUVENTUDE, CONSUMO, ALIMENTAÇÃO E PRÁTICAS DE COMER NA ESFERA DO ROCK
}

\section{Cláudia Peixoto Cabral ${ }^{1}$}

Festival de Rock com nome de fruta o Bananada faz homenagem a essa popular e apreciada iguaria em todo o território nacional. Evento musical e cultural que movimenta a cidade de Goiânia, capital do Estado de Goiás, anualmente no mês de maio. A capital de Goiânia é uma jovem cidade com 83 anos e 1,4 milhões de habitantes. Nem todo mundo é "rockeiro" no festival de música, que acontece na Esplanada Oscar Niemeyer, espaço projetado pelo arquiteto modernista, mas o acesso ao festival como evento descolado e jovem da cidade atrai um grande público, pessoas que pertencem a diferentes grupos sociais e faixas etárias. Público diversificado e diferente do que frequenta os palcos de rock alternativo da cidade e até mesmo do festival Bananada em seus primórdios ainda na década de 90 .

Este artigo busca utilizar realizar o diálogo entre alguns autores para empreender a compreensão da sociabilidade pelo consumo, práticas culturais e distinção e maneiras de comer em uma jovem capital do centro-oeste brasileiro no festival de rock Bananada. O evento cultural perpassa e relaciona-se com a dinâmica econômica e com as práticas de comer, não somente no espaço onde foi sediado o festival, mas em vários ambientes de lazer e entretenimento da cidade, restaurantes e bares.

O festival Bananada é um acontecimento anual que promove a ampla circulação de pessoas e tem uma proposta de ampliar processos relacionados ao comer, consumo e ação ${ }^{2}$. A ampliação das atividades além da cena musical e da realização de shows musicais de rock para práticas de sociabilidade e do comer, envolvendo restaurantes e bares é um dos

\footnotetext{
${ }^{1}$ Universidade Federal de Goiás, Brasil.

${ }^{2}$ A relação entre comer, consumo e ação; entre outras mudanças no comer incentivadas pelo processo de globalização, fluxos e acessos com abordagens que utilizam os conceitos de cultura são temas tratados no projeto de pesquisa "Consumo, cidade: o acesso ao alimento considerado saudável", do grupo de Pesquisa do CNPQ: GECCA (Consumo, Cultura e Alimentação), parceiro da REDE NAUS ( Rede Ibero-americana de Pesquisa Qualitativa em Alimentação e Sociedade). O GECCA é coordenado pela professora Janine Helfst Leicht Collaço da Faculdade de Ciências Sociais da Universidade Federal de Goiás, docente do Programa de Pós-Graduação em Antropologia Social desta instituição.
}

Iluminuras, Porto Alegre, v. 18, n. 45, p. 269-288, ago/dez, 2017. 
diferenciais que motivou a realização deste trabalho, que pretende analisar o entrelaçamento entre cultura, poder, a dinâmica econômica e alimentação.

Nesta perspectiva de consumo, ação, cultura, identidade e economia utilizo para reflexão considerações referências teóricas de Eric Wolf, Arjun Appadurai, Adam Kupper entre outros autores que contribuem para análise de questões relacionadas à cidades, antropologia e política cultural na era da globalização.

\section{Culturas, ampliação de público e de circulação de ideias e práticas de consumo}

Conhecida como a terra da música sertaneja, Goiânia e o estado de Goiás são assim considerados no imaginário coletivo. Na cidade um dos pilares da tradição que hoje é um fenômeno do show business no cenário musical do estilo sertanejo, acontece um dos maiores festivais de Rock do Brasil. O festival Bananada, realizado há 19 anos, desde 1998, é um dos mais antigos do país e tem um público significativo, movimentando a cidade com vários eventos e atrações musicais.

Transformações ocorreram desde a década de 90, o que era um festival de rock alternativo, realizado no Centro Cultural Martim Cererê, complexo público cultural da cidade onde funcionavam três caixas de água da SANEAGO (Companhia de Abastecimento de Água de Goiás) e foi revitalizado com a construção de três teatros de pequeno porte em 1988, atualmente possui investimentos públicos de projeto aprovado junto ao Fundo de Cultura e Arte do Estado de Goiás, com apoio e parceria privada de várias empresas e marcas. O evento acontece no Centro Cultural Oscar Niemeyer com uma área de 19.645 m2. Além da ocupação do espaço e de apoio e do aporte de financiamento chama atenção a ampliação do festival Bananada realizado durante quatro dias no maior complexo cultural da cidade e de uma estrutura de grande porte, com 6 palcos, que têm os nomes de marcas de produtos ou parceiros do festival, um público que, segundo a organização atingiu mais de 30 mil pessoas $^{3}$, sendo que outros shows acontecem durante a

\footnotetext{
${ }^{3}$ O festival é notícia em âmbito nacional. Matéria do Jornal o Globo, enfatiza valorização das atrações femininas no evento. Análise Bananada 2017 foi de Karol, Salma, Liniker, Gadu, Tulipa, Ceu, Luiza e tantas outras. Luccas Oliveira. Jornal O Globo Digital. 18 jun.2017. Disponível em: https://oglobo.globo.com/cultura/musica/analise-bananada-2017-foi-de-karol-salma-liniker-gadu-tulipa-ceu-
} 
semana, em vários palcos de casas noturnas de Goiânia e outra série de eventos ligados ao festival que tratarei mais à frente.

Para tratar da questão da cultura, identidade, consumo e alimentação e cidade chama a atenção a frase sobre na página oficial do festival de música. "Considerado um dos festivais mais importantes de todo o País, o Bananada chega à sua $19^{a}$ edição e coloca Goiânia mais uma vez no roteiro dos grandes eventos do Brasil. De 8 a 14 de maio, as experiências que o festival oferece vão muito além da música".

A proposta de "experiências além da música têm se implementado durante os 19 anos de sua realização e tem criado uma esfera, uma proposta de circulação de pessoas. bens, serviços e cultura diversificados na cidade. Portanto, nessa perspectiva a noção de cultura é uma questão importante para refletir sobre o processo de um festival de música, de rock propriamente dito como o é o Bananada, sendo que mesmo diante do senso comum de que Goiás e Goiânia são a terra da música sertaneja este evento coloca-se no sentindo de ampliar-se e expandir-se em tamanho, alcance de público, produção cultural, econômica e de oferecer múltiplas experiências, não somente as que dizem respeito às atrações musicais do festival.

O debate sobre cultura, ou culturas têm sido reificado e utilizado de forma ampla, a noção de cultura é um dos cernes de debates dos antropólogos, e há ainda uma captura da noção de cultura de forma ampla e de forma irrestrita.

Tudo que trata de diversidade ou de diferença passou a ser denominado "cultural", vemos, portanto, especificações que utilizam o termo cultural de forma abrangente. Um exemplo é o termo "Economia da cultura", entre outras tantas políticas públicas que enfatizam essa concepção. A cultura é dessa forma, termo político e construído como forma de estabelecer parâmetros de negociação, relações, circulação e permanências ou o direito a todas essas ações. A concepção de cultura têm significados e abordagens conceituais diferenciadas, mas para pensar as relações que permitem o trânsito, mudanças e fluxos.

luiza-tantas-outras-21348272.

Acesso

em:

20

jun.2017. 
Cultura como observou Marshall Sahlins, ou uma concepção que a este termo se relacione, "está na boca de todos", conforme salienta Adam Kuper ao explicitar de como a abordagem de cultura expandiu-se em amplas direções, da construção do discurso político ao mercado. "Além disso, não há como subestimar a cultura. Ela fala mais alto em termos de motivação do comportamento do consumidor", afirma o folheto da empresa, "é mais persuasiva do que a razão, mais 'massa' do que a psicologia”. (2002: 21).

A abordagem de cultura é utilizada em vários sentidos e sua teorização e questionamento teve um aquecimento entre 1920 e 1950, buscando-se encaixar esta concepção em categorias bem definidas com referências de autores do século 18 e 19, oque torna-se cada vez mais complexo devido ao uso amplificado que o termo alcançou no século XX, agravando-se essa situação na era da globalização.

Para contextualizar e problematizar o debate sobre cultura, juventude, cultura e alimentação na era da globalização, considero pertinente salientar que várias tradições refletiram sobre o termo cultura. Destaco para compreensão deste enfoque as tradições teóricas francesa, alemã e britânica, que possibilitam uma identificação da origem da concepção de cultura. Na tradição francesa o enfoque está ligado à capacidade exclusiva da humanidade proporcionada pela razão de criar de forma progressiva uma civilization, “cultura universal” em que a ciência poderia vir a contribuir com o processo.

A contrapartida dialética da tradição francesa é a kultur alemã que tinha como discurso a defesa da tradição nacional em oposição à civilização cosmopolita, de origem protestante defendiam os valores espirituais e as perspectivas emocionais e fundamentada no Estado-nação, como explica Kuper. "Ao contrário do conhecimento científico, a sabedoria da cultura é subjetiva" (Idem: 27). Outra tradição europeia a britânica também ensejou o debate de cultura, incitada pela transformação da revolução industrial, tinha como preocupação que a tecnologia transformasse o que era compreendida como civilização, fundamentada na tradição da arte e da filosofia, em que cultura significava valores que apoiavam a ordem social.

A antropologia tem na abordagem cultural, diversidades e diferenças e nestas problematizações como alguns dos seus principais questionamentos, sendo que a noção de cultura especialmente utilizada nos estudos culturais norte-americanos. Mas apesar desta 
opção da tradição norte-americana, em 1946, Parsons já enfrentava questionamentos a respeito de seu propósito de estabelecer a antropologia como uma "ciência da cultura" e a dificuldade de estabelecer um conceito de cultura. "Na teoria antropológica, ainda não existe um consenso a respeito da definição do conceito de cultura" (ibidem: 80).

Correntes teóricas e autores conceberam a noção de cultura de diferentes perspectivas na antropologia. Como referenciais à disciplina as abordagens: o evolucionismo e relativismo de Franz Boas de que para entender um fenômeno cultural é necessário observar a complexidade do passado; o estruturalismo de Claude Lévi-Strauss que compreende cultura como linguagem; noção que para Clifford Geertz é concebida como texto de acesso público e como um sistema, uma estrutura ordenada de símbolos e significados, a referência de Marshall Sahlins que tem influência da antropologia econômica em que a noção de cultura relaciona-se com materialismo e dimensão simbólica.

Ponderar essas concepções e abordagens teóricas é importante para que possa dar seguimento ao que temos como foco discutir, partindo de uma noção de cultura como uma sequência de operações que estão interligadas com a dimensão política e econômica e como processo e como fenômeno relacional dinâmico. "A razão pela qual precisamos de uma noção de cultura é de ordem moral ou política. O conceito de cultura nos fornece a única forma que conhecemos para falar sobre as diferenças entre os povos do mundo, diferenças que persistem a despeito do processo de homogeneização" (ibidem: 272).

Segundo Clifford Geertz, cultura é um contexto onde os processos, acontecimentos sociais, comportamentos e instituições podem ser descritos; também engloba modo de vida; legado social que o indivíduo adquire por meio da relação social com o grupo; forma de pensar, sentir e acreditar; conjunto de aprendizagem comum e de orientações padronizadas de comportamento; mecanismo de controle e regulamentação normativa de comportamento (2011: 8-10).

Há contribuições recentes na antropologia brasileira para pensar a noção de cultura, abordagem reificada e utilizada mundialmente de forma ampla para designar concepções em vários segmentos do conhecimento e do contexto social e político. A noção de cultura como categoria e sua relação com a antropologia, conforme Parsons, a "ciência da cultura", vem especialmente da tradição norte-americana e dos estudos culturais. As reflexões da 
antropóloga Manoela Carneiro da Cunha sobre cultura traz uma forma crítica de pensar cultura.

Para Cunha, cultura é uma construção para pensar o outro, um argumento político e uma invenção dos antropólogos e dialoga com Marshall Sahlins neste sentido. A definição de cultura e uso desta categoria é complicada e a sua ideia como construção e argumento político vem clarear o entendimento de como ela é secularmente utilizada para falar do outro, dos povos tradicionais, construção essa também semelhante aos conceitos de raça e identidade que também são argumentos políticos, de posicionamento de grupos sociais, mecanismos de dominação e de resistência. A autora enfatiza que muitos grupos sociais estão evidenciando sua cultura como forma de reparação a danos sociais e políticos. Apresenta uma noção de cultura, sem determinismos conceituais, que tem como enfoque uma abordagem além da diversidade, diferenças e fronteiras, contrastes e olhares, fundamentada nas relações estabelecidas no âmbito social.

Acredito firmemente na existência de esquemas interiorizados que organizam a percepção e ação das pessoas e que garantem um certo grau de comunicação em grupos sociais, ou seja, algo no gênero do que se costuma chamar de cultura. Mas acredito igualmente que esta última não coincide com "cultura", e que existem disparidades significativas entre as duas (2009: 313).

Complicada e intrínseca e com tradições europeias sempre ligadas às relações de poder, a cultura também passa pelo processo de reinscrição e reinvenção. Kwame Anthony Appiah discute esta questão de cultura pura que contribui para pensar a proposta deste trabalho. "When people speak for an ideal of cultural purity, sustaining the authentic culture of the Asante or the American family farm, I find myself drawn to contamination as the name for the counter-ideal. Terence had a notably firm grasp on the range of human variety: "So many men, son many opinions" was an observation of his". (2007: 240).

A aceitação de que fronteiras culturais não são fixas e que há circulação e fluxos e constante negociação entre os grupos no âmbito social não era uma ideia que esteve presente na antropologia norte-americana. No processo de globalização assim como em outros períodos da história a cultura, a diversidade e as diferenças estão em constante 
transformação, como é possível analisar na observação do festival de Rock Bananada, suas próprias ampliações e mudanças.

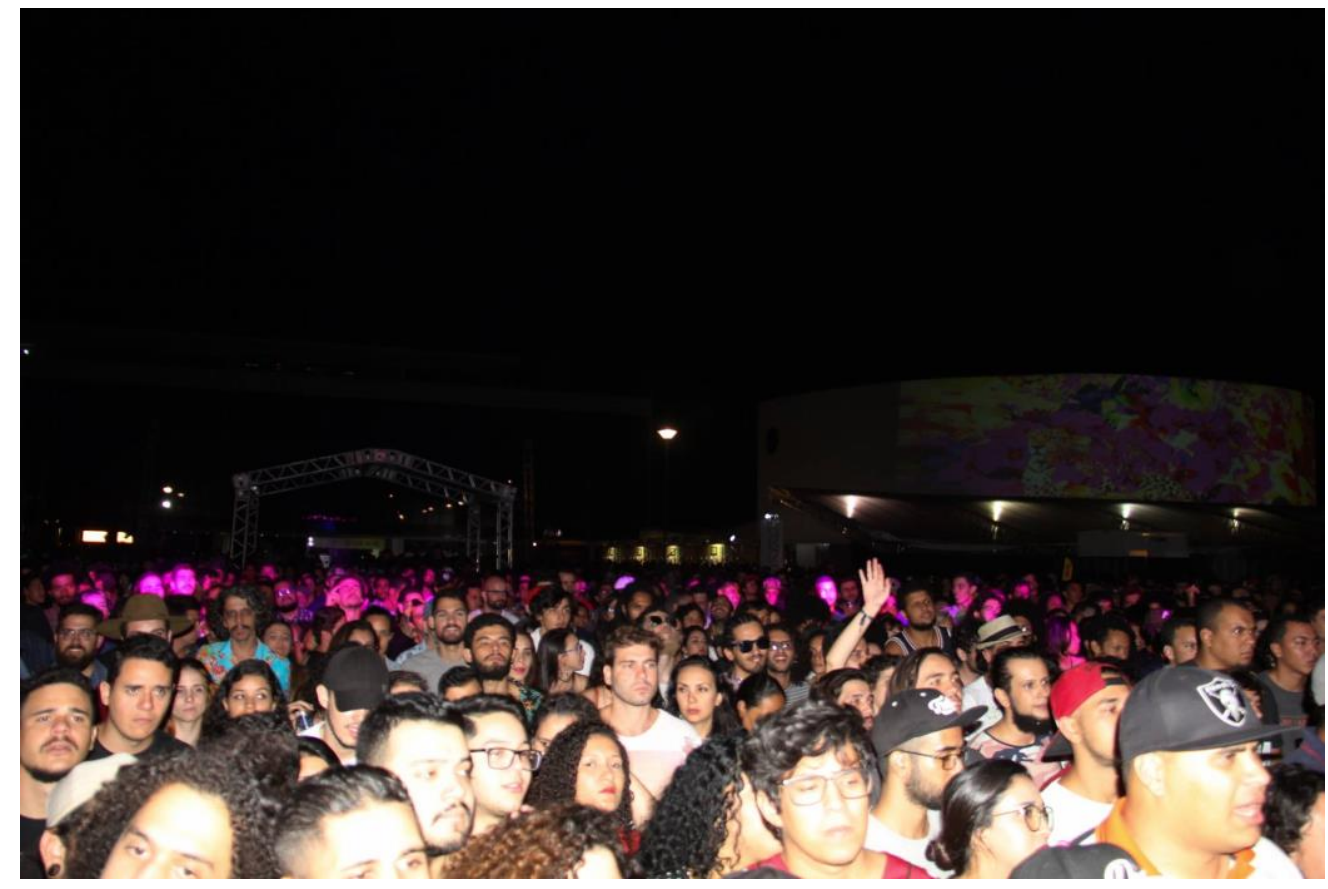

Figura 1: Festival Bananada 2017, domingo 14 de maio. Público aguarda o show do rapper Mano Brown no Centro Cultural Oscar Niemayer, palco Chilli Beans Acervo da autora.

No caso do festival, que começou independente e de alcance a um público reduzido e determinado e registrou-se uma expressiva ampliação, houve um fenômeno de negociação, disfunção, alteração da proposta inicial ou uma transformação, do que entendese pelo o que pode ser considerado de "independente e ainda de "cultura goiana". O estado de Goiás tem tradição rural de padrões de comportamento compreendidos como "caipira" que são absorvidos pelo senso comum e o imaginário coletivo.

Outra contribuição importante para pensar esse processo são as ideias de Henriqueta L. Moore, que dialogam com a noção de cultura de Manoela Carneiro da Cunha de que cultura é dinâmica, a cultura não aprisiona, os processos culturais e de interação promovem fluxos e mudanças. Para tratar desta abordagem de fluxos, a autora faz uma crítica sobre a reificação da cultura e a sua concepção como algo estagnado e fechado, principalmente na era da globalização, e pondera que esse é um debate essencialmente político. 
Hanrrinson argues that while the objectification and commodification of culture are not new what has changed over time is the notion of property that underpins Melanesian concepts of culture. His central thesis is that contemporany views of culture, largely because of political mobilisation against colonial powers and the development of nationalist and inter-ethics politics, are now based on the notion of culture as a reified possession, one that is holistically conceived as belonging to a unique and bounded group. From this perspective, cultural groups are depicted emities to which people have fixed and exclusive affiliations, and culture is something that belongs not only to its creators, but more crucially to their heirs (2007: 22).

O festival de rock em pleno berço da música sertaneja desafia essa cultura, essa forma de produção simbólica e construção de identidade dada e colocada como "cultura raiz" manifestada em bens de lazer e entretenimento, shows, vestimentas, modos de ser e agir que produz uma ampla rede de bens, serviços e consumo e que se coloca como prática de poder e patrimônio. Cultura e patrimônio que relaciona-se com o poder de determinar e definir o que é, merece e deve ser preservado e mantido como memória como repertório simbólico. Negociações culturais regionais, nacionais e globais enraizadas nas trama das relações de poder, sugere Nestor Canclini.

“O patrimônio cultural funciona como recurso para reproduzir as diferenças entre os grupos sociais e a hegemonia dos que conseguem um acesso preferencial à produção e à distribuição dos bens". (Canclini: 195). Rede de relações que estão inseridas nos sistemas políticos, econômicos e sociais em que a cultura coloca-se como mecanismo de condução. Desta forma buscarei demonstrar que a partir das transformações de um festival independente de rock acontece uma intensa circulação de pessoas, em variados espaços e diversos ajustes aí implicados.

\section{Consumo, cultura e alimentação}

A programação do Festival Banana que aconteceu de 8 a 14 de maio de 2017 em Goiânia foi uma das mais amplas nesses 19 anos de edições do evento. Além do que os produtores culturais chamam "Bananada nas casas", com shows em várias casas noturnas da cidade. Uma ampla programação de esporte e arte, projeção da produção de grafites, festival de tatuagens, campeonato de skate, loja de roupas, espaço infantil com atividades para as crianças aconteceu pelo quinto ano consecutivo o que os organizadores chamam de 
"Circuito gastronômico goiânia rock city + batalha de chefs", assim explicitado em destaque em materiais de divulgação do Festival Bananada 2017.
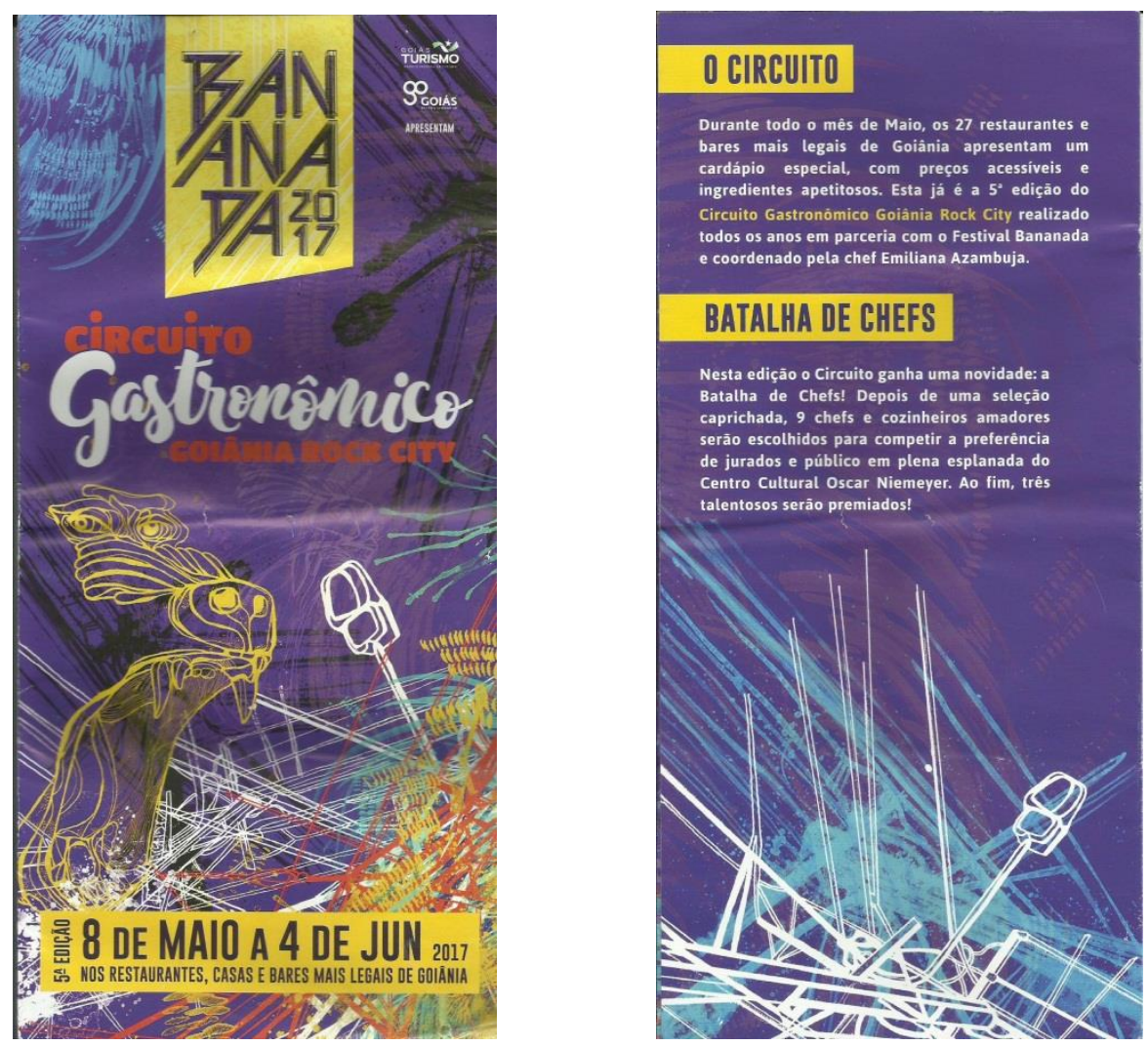

Figura 2: Folder informativo da batalha de chefs e circuito gastrônomico.

Eventos relacionados à alimentação e ao comer alinhavam o que mencionei neste artigo, utilizando as frases de Adam Kuper ao que se refere aos usos da noção de cultura, em que essa ideia promove e amplia a circulação e motiva padrões de comportamento do consumidor.

A chamada de matéria na capa do maior jornal de circulação do Estado, O Popular enfatizava "Rock com sabor, Circuito gastronômico que integra Festival Bananada inclui quase 30 bares e restaurantes". A matéria interna de uma página anunciava o lançamento do Circuito gastronômico Goiânia Rock City, em um bar da moda da juventude de classe média alta no setor Marista, como um mais um evento paralelo ao festival de rock. No serviço do jornal os bares, restaurantes, cafés e confeitarias são mencionados como pontos 
culturais. Intitulada "Bananada no prato" a matéria está ilustrada com duas sobremesas, uma criada por uma das mais famosas confeitarias da cidade no formato do Centro Cultural Oscar Niemeyer e uma outra opção de um café sediado também no setor Marista, como já mencionei área nobre da cidade, de uma torta de palha italiana, ainda na página a foto de uma outra receita criada para o festival por um restaurante lasanha de espinafre, ricota e abobrinha.

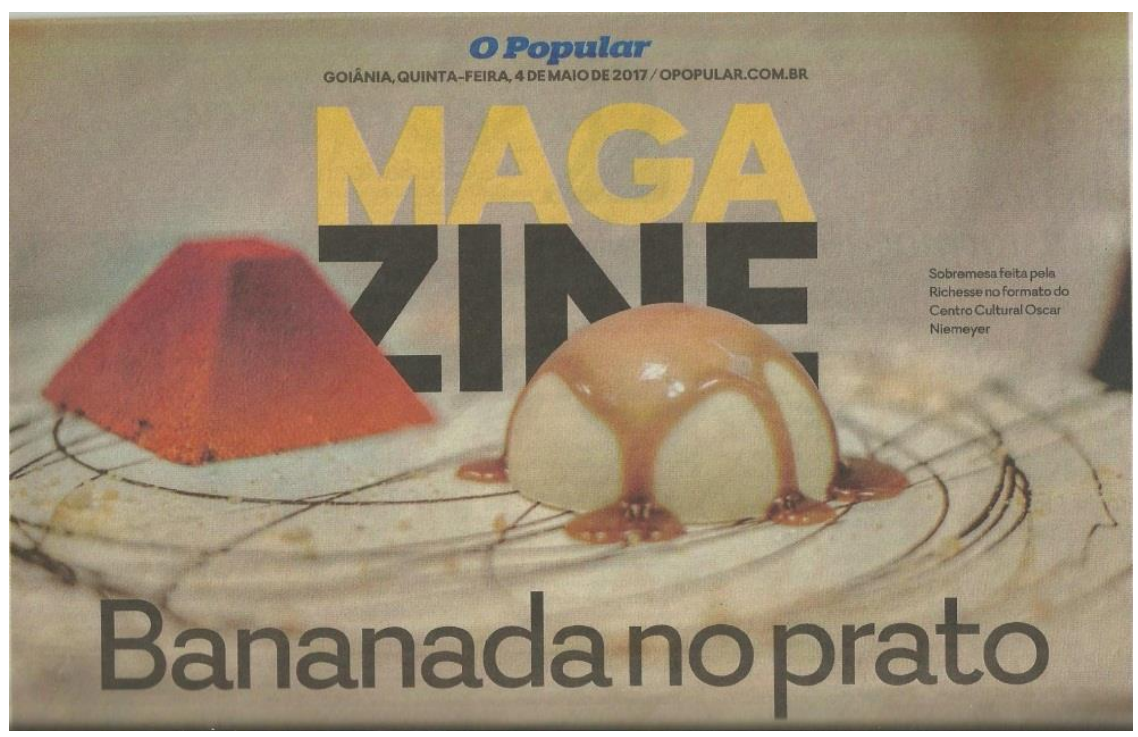

Figura 3: Matéria publicada no jornal diário de maior circulação de Goiânia.

Ao todo vinte e sete bares, restaurantes, cafés, sanduicherias e confeitarias criaram suas receitas de comida passam dessa forma a fazer parte do festival e espaços do comer e beber serem chamados de pontos culturais de Goiânia ${ }^{4}$. O que remete ao que busco apresentar nesta análise de como cultura é processo, negociação, fluxo e circulação. São

\footnotetext{
${ }^{4}$ No quinto ano em que o festival Bananada amplia a circulação além da experiência da música para a experiência do sabor e em que o espaço do comer e a comida passa a ser tratada como bem cultural estes foram os participantes : Empório Saccaria, Tribo do Açaí, Velvet 36, Ateliê, República da Saúde, Antônia Bistrô, Las Nenas, Comes Ambiente, Bar do Piry, Cawa Burguer, Tio Bakinas, Diablo Bar, Dox Store, Rock, Quinta do Minho, Panela Mágica, P di Pizza, Bão Bar, Shiva Art Bar, Mandalas, Richesse Confeitaria, Hambúrguer e Café Autentico, Restaurante Victori, Sabor d Casa, Rocket 07, Brioche Sucre e Best Açaí. Diablo Bar, Dox Store, Rock, Quinta do Minho, Panela Mágica, P di Pizza, Bão Bar, Shiva Art Bar, Mandalas, Richesse Confeitaria, Hambúrguer e Café Autentico, Restaurante Victori, Sabor d Casa, Rocket 07, Brioche Sucre e Best Açaí.
} 
cinco edições em que o festival amplia por toda a cidade suas influências em cardápios e práticas do comer. As receitas do circuito foram mantidas durante todo o mês de Maio, com preços divulgados como acessíveis ao público, valores entre $\mathrm{R} \$ 5$ e $\mathrm{R} \$ 68,00$. As práticas do comer no festival e a seleção das receitas foram realizadas e coordenadas pela chef de cozinha Emiliana Azambuja que, em entrevista ao jornal, enfatiza a proposta de fluxo e circulação que esta análise tem como foco e observação. "É um mergulho de cabeça nos experimentos desenvolvidos na cozinha goiana. Temos um cardápio próprio que circula em todas as casas e selecionamos pratos e lugares com propostas interessantes e menus inovadores" 5 .
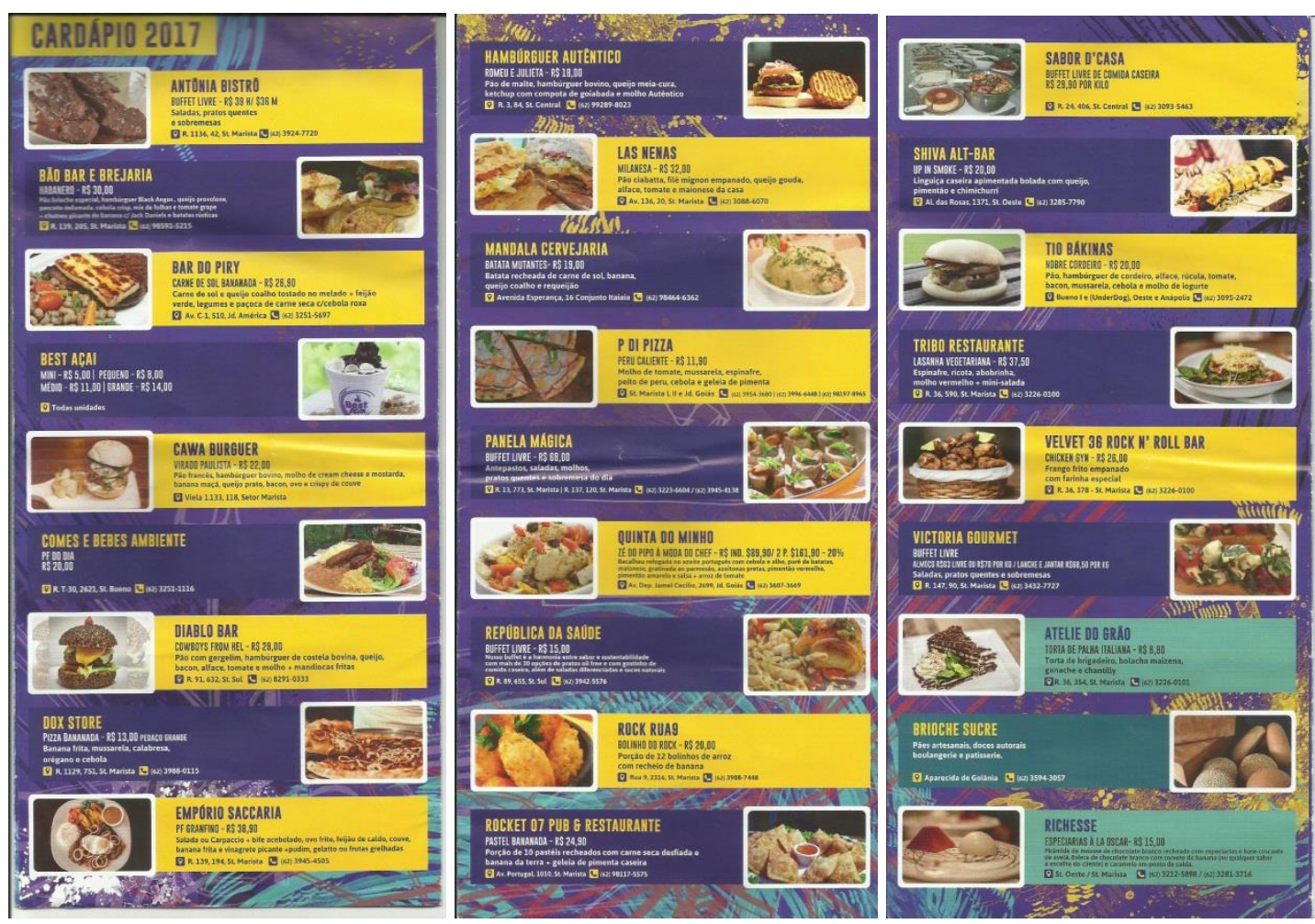

Figura 4 : Folder do circuito gastronômico do Festival Bananada, divulga os estabelecimentos, endereços e pratos.

\footnotetext{
${ }^{5}$ Jornal o Popular do dia 4 de maio de 2017, em matéria jornalística de Bruno Félix a relação entre o comer e o evento cultural. Tanto na chamada de capa, quanto na matéria principal, que ocupa uma página do jornal formato tablóide evidencia-se em gênero noticioso e de caráter de serviço ao público leitor com ênfase entre a relação comida "Circuito gastronômico" e a cultura "o festival de Rock bananada".
} 
A relação do Festival Bananada como procuro demonstrar, cultura, e comida, em 2017 incorporou mais uma transformação e proposta de circulação de pessoas e espaços ao promover a competição Batalha de Chefes, que descreverei mais à frente, além da tradicional praça de alimentação. Outros espaços de em que a alimentação está presente. Assim como a música que se expande e se amplia no processo de transformação do evento cultural, ela está dentro e fora do espaço principal do Festival Bananada o Centro Cultural Oscar Niemeyer. A alimentação também se espalha como atrativo e tipifica-se em produto da cultura, e transforma espaços de comer em como já abordei acima em pontos culturais.

Dentro desta perspectiva é o que é possível observar a condição da alimentação enquanto produto relacional em constate fluxo e que estabelece uma subjetividade, imprime valor e promove identificações e identidades políticas. No caso do Festival Bananada a identidade da juventude, que aprecia rock e que contrasta com a tradição da cidade de tradição caipira e música sertaneja. É dessa forma e em dinâmicas como esta observadas no Festival Bananada que podem-se verificar como as questões de identidade, pertencimento fazem parte de um rede de processos e ajustes, que Janine Collaço aborda em seu trabalho sobre a cozinha italiana em São Paulo.

"Comida fala de identidade o tempo todo e se apropria de ideias que circulam em torno de emblemas nacionais e regionais, entre famílias, posição social, idade e que é manipulada a partir de relações sociais" (2011: 215).

É neste ponto ao refletir sobre a questão da identidade, do consumo, cultura e que o poder se coloca na perspectiva da alimentação. Portanto, nesta análise observei que a alimentação relaciona-se com o festival de rock como uma questão de identidade e de circulação em espaços. Percebe-se que neste contexto o comer coloca-se como um posicionamento de ação de cultura e consumo.

Apesar de identidade ser uma noção complexa de ser utilizada, sua concepção está diretamente ligada a uma construção de caráter político que enfatiza distinção e posicionamento e propaga posições de grupos sociais. Agregar comida ao festival é uma opção de realizar essa marcação da diferença entre um festival de rock e um evento sertanejo. Constrói uma representação, imprime refinamento, criação, paladares e promove 
identificações com as pessoas. Comida reúne gente, gostos, ideias, sabores e de forma infinitamente globalizada grupos de pessoas.

O festival torna-se uma representação coletiva da juventude, de acesso e de consumo. A representação coletiva promove uma neutralização de diferenças, como abordava Wolf em seu artigo sobre a virgem de Guadalupe no México antecipando a noção de comunidade imaginada de Anderson. Trata-se, portanto, não de refletir sobre o caráter nacional, mas utilizar essa referência para refletir como fenômenos simbólicos promovem processos de interação, de identificação e de pertencimento. Se no caso mexicano da virgem de Guadalupe analisado por Wolf de pertencimento ao nacional, no caso do festival Bananada um processo de pertencimento nacional e do mundo globalizado do rock e de inclusão em um evento que já está presente no calendário brasileiro como um dos mais antigos e tradicionais de rock independente do Brasil.

Trata-se também de observar que em dezenove anos de festival houve a ampliação da circulação de pessoas em espaços imaginados e refinados e de acesso à elite econômica e social, proporcionado pelo tempo, o trabalho dos produtores e também pela comida. Alguns espaços de comer relacionados na página dos participantes do circuito gastronômico não seriam de acesso do público de um festival de rock alternativo como o Bananada no final da década de 90 , ou o público do restaurante não estaria interessado ou sequer saberia do que tratava esse evento cultural.

No entanto, o que a análise desse processo apresenta é que no decorrer do tempo ocorreu o fluxo, entre o independente subversivo, transformado em evento cultural "descolado" da juventude. Esta negociação fez ainda que durante o festival espaços de comer sejam tratados como pontos culturais. Esses processos chamam atenção e especialmente é possível considerar a concepção de Aníbal Quijano de que a subversão, se vitoriosa, cria uma nova hegemonia. $\mathrm{O}$ uso do conceito de hegemonia nem sempre pode ser compreendido de forma clara, mas utilizo essa perspectiva para analisar o processo de transformação da circulação fluxo e acesso.

Os jovens produtores culturais da década de 90 eram rockeiros da cidade, que lotavam o festival em um espaço de fronteira. Apesar do caráter de subversão dos festivais esses jovens com acesso aos conhecimentos, às relações de poder e às leis de incentivos 
culturais foram ampliando a circulação do antes subversivo e independente festival Bananada, que hoje movimenta, instiga uma parcela significativa de grupos sociais em fazer parte deste momento efêmero que é um festival de rock em sua própria cidade. Não é só música, é também o fazer parte, circular, ver e ser visto.

Se ocupar espaço é se estabelecer e posicionar-se politicamente digamos que a comida têm se destacado nesta proposta de existência do festival Bananada como essa nova hegemonia, como já mencionei. Ao chegar ao evento um corredor de barracas de vendedores ambulantes se aglomeram uma ao lado da outra. Além de bebidas, as comidas de rua estão por toda a parte, espetinhos, sanduíches, cachorros quentes, batatas fritas, de forma diferente de outros festivais, porque em São Paulo essas aglomerações de barracas fixas, sobretudo de comida, não são visualizadas com tanta frequência, talvez por não serem permitidas.

Dentro do festival a comida é servida na praça de alimentação, Vila gastronômica, montada em espaço que pode ser considerado centralizado ao lado da pista de Skate e próximo ao palco principal onde se apresentavam as maiores atrações do festival. As opções de comida são em média no valor de $\mathrm{R}$ \$25,00 não limitava-se a sanduíches. Há uma variedade de opções, uma diversidade que chama atenção para o que afirma Kwame Appiah que o consumo promove a circulação e não homogeiniza. "Talk of cultural imperialism struturing the consciounesses of those in the periphery treats Sipho and people like him as tabalae rasae on which global captalism's moving finger writes its message, leaving behind another homonized consumer as it moves on. It is deeply condescending. And isn't true" (2007: 240).

Observando a praça de alimentação do festival Bananada essa é uma afirmação que podemos considerar pela quantidade de opções e variedade de opções de alimentação. 


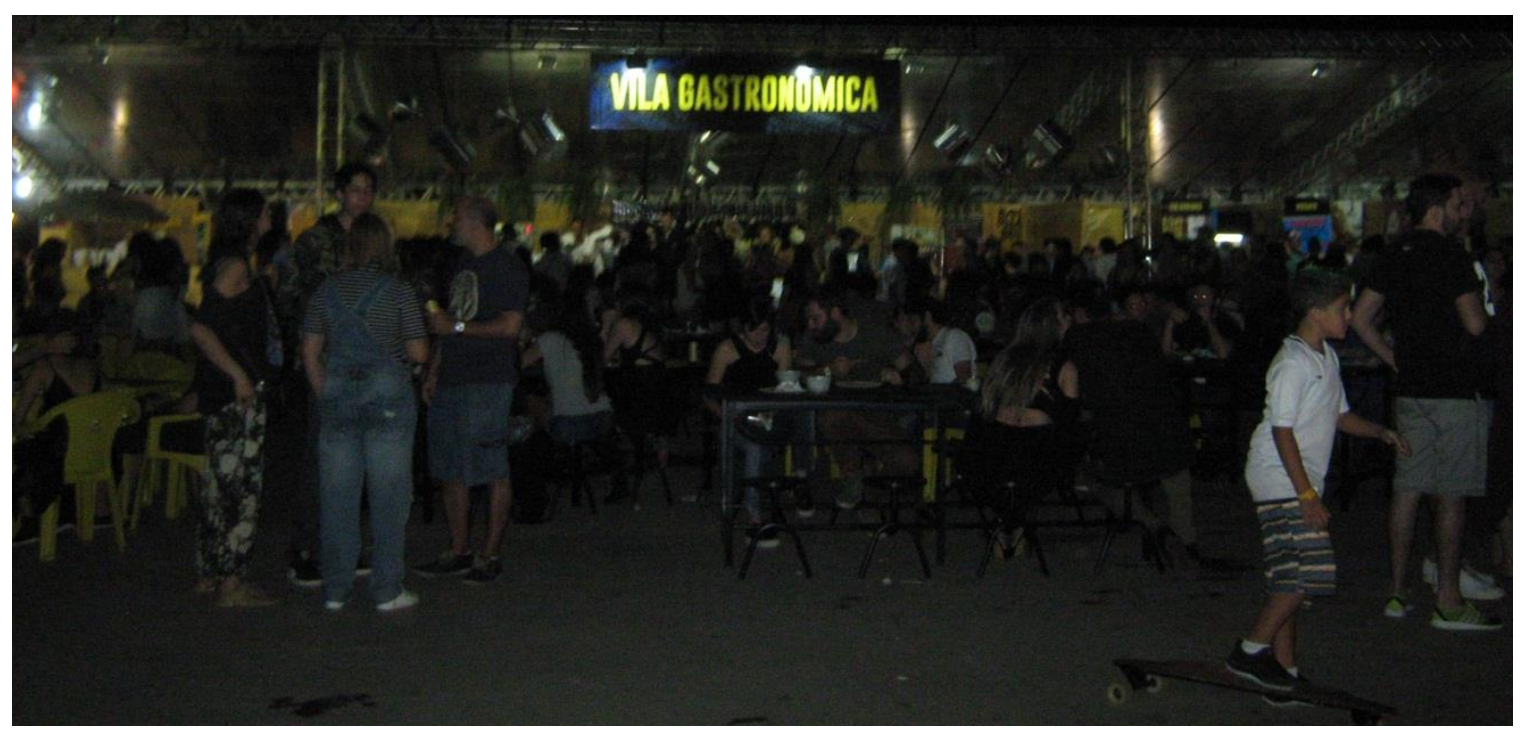

Figura 5: Público na Vila Gastronômica do Festival Bananada. Acervo da autora.

Os balcões de venda estão todos cheios, as filas ficam enormes no intervalo dos shows e até ao mesmo tempo em que eles aconteciam. As opções são variadas: Yakisoba; Sushi; Chiken and potatos; Sanduíches; Risotos; Pipoca Gourmet. Pessoas faziam filas aguardando o pedido de seu prato, enquanto outras disputavam as mesas, apesar de terem sido colocadas em boa quantidade, que estavam dispostas em frente aos balcões montados em madeira.
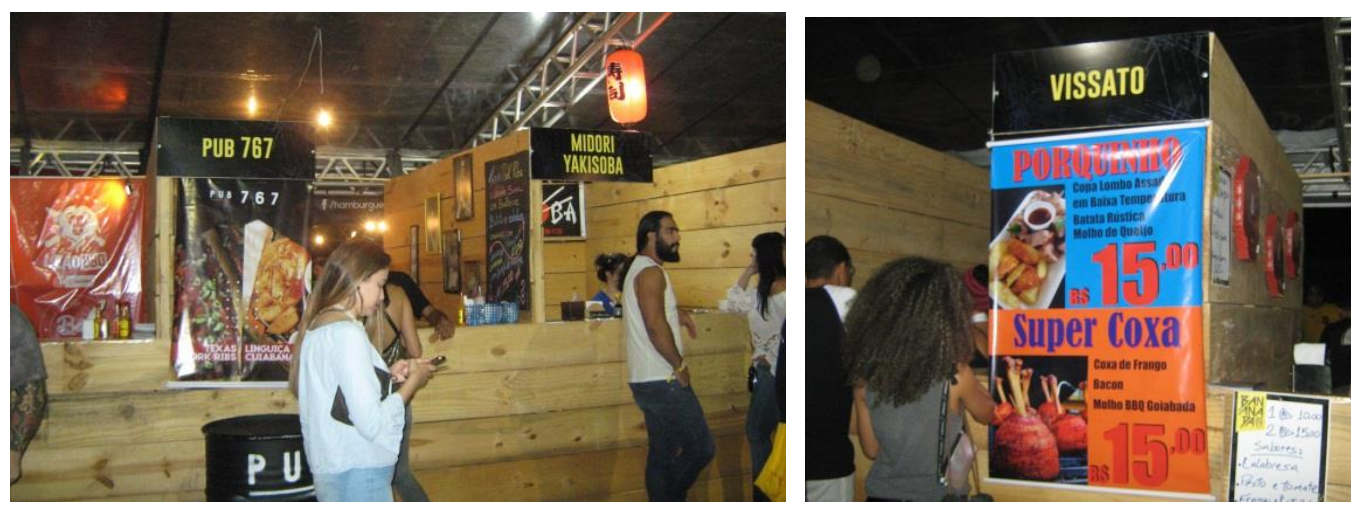

Figura 6 e 7: Opções e práticas do comer no festival de Rock. Acervo da autora. 
Entre os guichês de servir comida uma área reservava o espaço onde aconteciam pela primeira vez no festival as batalhas do Chefs, outra ampliação do festival Bananada relacionada às práticas do comer. Em mesas dispostas em frente aos balcões mais baixos onde eram exibidas as comidas vencedoras, os jurados terminavam o seu trabalho de ver e degustar qual sabor deveria ser o ganhador em três categorias de preparo de alimentos: orgânicos (vegetarianos e veganos), suínos ou doces. A decoração do amplo espaço centralizado da batalha de chefs chamava a atenção, panelas penduradas, colheres, uma grande cozinha industrial montada e grandes estantes cheias de alimentos, frutas e verduras de tons, verdes, amarelos, vermelhos, arroxeados, completavam a paisagem de sabor. Observei que os candidatos estavam recebendo a premiação de $\mathrm{R} \$ 1.000,00$. As pessoas estavam animadas e felizes, alguns jurados continuavam a comer, mas a premiação e a exposição dos vencedores já aconteciam.

Os pratos vencedores estavam expostos na bancada em posição de destaque. A seleção era realizada por nove chefs e podiam participar do concurso cozinheiros amadores. Além da premiação em dinheiro os três vencedores também recebiam um forno elétrico. A batalha de Chefs no Festival de Rock Bananada é mais uma experiência de inovação e ampliação do evento relacionada às práticas do comer. No espaço preparado e montado exclusivamente para a competição, uma ampla presença de marcas de produtos. Durante o trabalho de campo realizei, acontecia a premiação, logo após a divulgação dos vencedores o espaço estava sendo desmontado, não sendo possível contabilizar quantas marcas de produtos alimentícios expunham seus produtos, seria necessário mais tempo para o levantamento, o que não foi possível durante a observação participante para a elaboração deste artigo.

Ao mencionar o objetivo de realização da premiação a coordenadora do evento Batalha de Chefs no Festival Bananada, chef Emiliana Azambuja, em entrevista ao veículo de imprensa reitera à abordagem antropológica de circulação e fluxos que busco abordar nesse trabalho. "Nunca tivemos nada parecido em Goiânia. É um projeto que deseja desenvolver uma mobilidade entre diferentes formas de se enxergar a gastronomia por meio 
de categorias pré-definidas e dar uma cor mais ao nosso projeto, que é algo que já se consolidou na programação do Bananada" 6 .

No decorrer do trabalho de campo, pude constatar outra modalidade de oferta de alimentos além das opções da Vila Gastronômica, localizada no espaço "nobre" do festival, mais centralizado, próxima aos palcos, a entrada e a pista de skate. Em um local afastado próximo ao palco dos Djs, onde não havia os shows de atrações de destaque do festival e atrás de uma loja de roupas de grande proporção encontrei a área de Food Trucks. Haviam seis carrinhos que serviam comidas de rua, espetinhos; pastéis; tapiocas salgadas, veganas e doces; sushis de batata, milk sake e sanduíches com preços entre R\$10 a 20,00 .

Conversando com os trabalhadores e atendentes dos estabelecimentos comerciais era notável que eles sentiam-se isolados no espaço a eles reservado. Maiara que trabalhava no carrinho de pastel mencionou incômodo com o isolamento.

Julio do carrinho dos espetos afirmou considerar que a logística da compra de fichas atrapalhava que as pessoas consumissem os alimentos dos carrinhos. "Aqui não vende fichas, muitas pessoas não sabem que têm Food Truks aqui e quando descobrem pela primeira vez, querem comprar, mais não têm fichas. Ficam desanimadas de voltar porque é longe, mas tem gente que volta no outro dia". Quando perguntei sobre o horário de maior movimento, André que atendia nas tapiocas disse que era o momento do intervalo dos shows.

O carrinho mais cheio era o de sanduíches e, segundo um interlocutor, somente a marca Tio Bákinas tinha a licença para o comércio com exclusividade. Alcides o interlocutor que conversei que trabalhava no carrinho do milk shake era mais animado com o resultado das vendas na área dos Food Trucks. "Valeu participar do festival! O mais importante pra nós também é divulgar e associar a marca ao nome do festival, porque temos três carrinhos, este que faz eventos e mais dois com como ponto fixo no Quintal e Sabores Food Trucks.

\footnotetext{
${ }^{6}$ Félix, Bruno. Batalha no prato. Jornal O popular. 4 de mai. 2017.
} 
Há, portanto, coincidências e propósitos que observei como comuns, tanto na área da Vila Gastronômica, quanto na área mais afastada dos Food Trucks. Entre elas a que chama mais a atenção dizem respeito à Batalha de Chefes e aos carrinhos de Food Trucks. Pude perceber que as duas propostas têm basicamente como objetivo principal a circulação de marcas entre o público jovem e associar suas propostas ao nome do festival, visando à ampliação de vendas e negócios.

O trabalho de campo e observação participante descrita foi realizada no domingo, último dia de festival, proporcionada pela ausência de cobrança do ingresso no valor de $\mathrm{R} \$$ 40,00 em homenagem ao dia das mães, exatamente o último do evento 14 de maio. As mães poderiam ganhar a entrada mediante a apresentação da certidão de nascimento dos filhos, essa foi uma oportunidade para realizar esta sucinta etnografia das práticas do comer no festival do Rock Bananada.

\section{Considerações finais}

$\mathrm{O}$ debate que pretendi realizar neste artigo tem como foco a abordagem entre economia e cultura. Eventos culturais sazonais, a exemplo deste segmento do Festival de Rock Bananada, como espaço de dinâmica cultural e construção de espaços de poder e consumo.

A teoria antropológica recente tem chamado atenção para o fato de que as relações entre cultura e economia foram deixadas de lado pelos antropólogos. No entanto, este artigo buscou este debate instigado pelas considerações de Arjun Appadurai, do que o autor chama de "aspirações" e a concepção de que a antropologia não pode estar descolada do projeto de vida que perpassa as relações econômicas. A ideia é que a aspiração em si e os desejos estão intrinsicamente ligados ao consumo e ao acesso de bens e serviços. Para o autor, é necessária uma reflexão sobre essa distinção e a separação entre economia como a ciência do futuro e a antropologia e a cultura como uma ciência ligada ao passado. Portanto, essa é uma ambivalência que deve ser questionada e superada. (2007: 30). 
Outro autor que contribui nesse diálogo é "Eric Wolf que foi um dos pioneiros nesse sentido e que utilizou o marxismo para redefinir a antropologia" (Ribeiro: 267). Eric Wolf em seu trabalho crítica aos paradigmas culturais de Ruth Benedict e busca dar uma dimensão econômica e política à abordagem antropológica. Contribuições de Eric Wolf trata do Campesinato, em que analisa o contexto do sistema capitalista em expansão em processos sociais. A opção de Wolf é por aspectos das relações de grupos em sociedades complexas, termo utilizado para explicar a abordagem e o trabalho de Wolf sobre grupos sociais urbanos.

"Eu estava interessado em como as coisas mudam e ela como as coisas se mantêm" (Ghani, 1987: 357). Segundo Gustavo Lins Ribeiro e Bela Feldman, as reflexões sobre como a sociedade se transforma ao invés de como ela se mantêm era uma preocupação da antropologia na época, final da década de cinquenta em que tratam os trabalhos de Wolf sobre a nação e estado-nação, uma corrente que ocorria decorrente do avanço do capitalismo, discussão ainda recorrente no processo de globalização em que "A Redes de Relações Sociais" de Nobert Elias que exerceu influência no trabalho de Eric Wolf e sua perspectiva de entender como a sociedade se transforma.

O que procuro demonstrar é que, além da necessidade de levar em consideração as múltiplas faces do regionalismo em um país de diversidade como o Brasil também é inegável que os antropólogos busquem em suas análises ponderar sobre as transformações contemporâneas e da era da globalização. A cultura não é totalizante e homogênea, é dinâmica e promove a criação de fluxos e formas de apropriação de espaço e do tempo. $\mathrm{O}$ tempo de lazer e de comer é relacional, assim como comida pode ser concebida como material cultural e construção e circulação de imaginários, ideias e aspirações. 


\section{Referências}

APPADURAI, Arjun. Moodswings in the anthropology of the emerging future. Hau,: Journal of Ethnographic Theory, 6(2), 2016.

. The Capacity to Aspire: Culture and Therms of Recognition. In: Cultural politics. A Oneworld book: Oxford. 2007.

APPIAH, Kwame Anthony. Cosmopolitan Contamination. In: Cultural politics. A Oneworld book: Oxford. 2007.

CANCLINI, Nestor Garcia. Culturas Hïbridas. São Paulo: EDUSP, 1998.

COLLAÇO, Janine Helfst Leicht. Imigração e cozinha italiana na cidade de São Paulo: concepções de fartura e distinção. Anuário Antropológico/ 2011-I, 2012. . Consumo, cidade: o acesso ao alimento considerado

saudável, do grupo de Pesquisa do CNPQ: GECCA (Consumo, Cultura e Alimentação).

CUNHA, Manuela Carneiro da. Cultura com aspas. São Paulo: Cosac \& Naif

GEERTZ, Clifford. A interpretação das culturas. Rio de Janeiro: LTC. 2011.

KUPER, Adam. Cultura: a visão dos antropólogos. Bauru/SP: EDUSC, 2002.

MOORE. Henriquetta L. The Problem of Culture. In: Cultural politics. A Oneworld book: Oxford. 2007.

QUIJANO, Aníbal. Colonialidad del poder, cultura y conocimiento en América Latina. In: Dispositio, vol. 24, no.51, 1999.

ORTNER, Sherry. Dark Anthroplogy and th other: theory sunce the eighties. In: Hau,: Journal of Ethnographic Theory, 6(1), 2016.

RIBEIRO, Gustavo Lins; BIANCO, Bela Feldman. Antropologia e poder contribuições de Eric Wolf. Etnogtráfica, Vol.VII (2), 2003. Pp. 245-281.

WOLF Eric. Cultura, ideologia e poder: o futuro da antropologia. Mana, 4(1), 1998.

Matérias jornalísticas

Festival Bananada terá mais de 100 atrações em Goiânia. Disponível em: <http:/g1.globo.com/goias/noticia/2017/03/festival-bananada-tera-mais-de-100-atracoes-emgoiania-confira-lista.html>. Acesso em: 08 mai.2017.

FELIX, Bruno. Bananada no prato: Gastronomia. Quinta edição do Circuito Gastronômico Goiânia Rock City reúne quase 30 bares e restaurantes durante um mês na capital. Jornal O popular, Goiânia, 4 mai.2017. Magazine, p, M-1.

OLIVEIRA, Luccas. Análise Bananada 2017. Jornal O Globo Digital. 18 jun.2017. Disponível em: <https://oglobo.globo.com/cultura/musica/analise-bananada-2017-foi-dekarol-salma-liniker-gadu-tulipa-ceu-luiza-tantas-outras-21348272.> Acesso em: 20 jun.2017.

Recebido em: 15/10/2017.

Aprovado em: 15/11/2017. 